\title{
A Social Marketing Intervention to Prevent Drowning Among Inner-City Youth
}

Tavis J. Glassman, PhD, MPH, MSEd, MCHES, CCPH ${ }^{1}$

Tom Castor, MA, CTRS ${ }^{1}$

Monita Karmakar, $\mathrm{MS}^{1}$

Alexis Blavos, $\mathrm{PhD}$, MCHES $^{2}$

Paige Dagenhard, PhD, L/RT, CTRS ${ }^{3}$

Julianne Domigan, MA, CTRS ${ }^{1}$

Erin Sweeney, $\mathrm{MEd}^{4}$

Aaron Diehr, PhD, CHES $^{5}$

Ruthie Kucharewski, PhD, CTRS ${ }^{1}$

Background. Water-related injuries and fatalities pose serious public health issues, especially to African American youth, a demographic group that drowns at disproportionately high rates. Aim. The purpose of this study was to determine if a social marketing intervention targeting the parents and guardians of inner-city youth (U.S. Midwest) could positively influence their perceptions concerning water safety. Method. Researchers employed a quasi-experimental design using matched pairs to evaluate the intervention. Participants consisted of parents who enrolled their children in a six-session survival-swimming course. Guided by the Health Belief Model, the researchers disseminated six prevention messages using six different channels (brochure, e-mail, SMS text message, postcard, Facebook, and window cling). Results. The findings from a two-way analysis of covariance revealed that treatment group participants' knowledge and perceptions of water-related threat all changed favorably. Additionally, all participants planned to reenroll their children in swim lessons. Discussion. A social marketing campaign using the Health Belief Model improved inner-city parents' knowledge regarding water safety and enhanced their self-efficacy. Conclusion. This study provides practitioners with feasible strategies (prevention messages) to supplement swim lessons,

Health Promotion Practice

March 2018 Vol. 19, No. (2) 175-183

DOI: $10.1177 / 1524839917732559$

(C) 2017 Society for Public Health Education with the ultimate goal of preventing drowning among at-risk youth.

Keywords: drowning; children; youth; prevention; at-risk

\section{INTRODUCTION}

Water-related injuries and fatalities constitute major public health concerns. Each day, an estimated 10 people die from an unintentional drowning, and among those people, 2 are 14 years old or younger (Centers for Disease Control and Prevention [CDC], 2012). Drowning

${ }^{1}$ University of Toledo, Toledo, $\mathrm{OH}$, USA

${ }^{2} S U N Y$ Cortland, Cortland, NY, USA

${ }^{3}$ Western Carolina University, Cullowhee, NC, USA

${ }^{4}$ Baldwin Wallace University, Berea, OH, USA

${ }^{5}$ Southern Illinois University, Carbondale, IL, USA

Authors' Note: The research team would like to thank Wanda and Tankeeya Butts as well as The Josh Project Foundation for their collaboration with this research project. The financial resources for this study were provided via a grant from the Center for Injury Research and Policy funded by the Centers for Disease Control and Prevention. Address correspondence to Alexis Blavos, Assistant Professor, Health Department, SUNY Cortland, 15 Graham Avenue, Moffett, Center, Room 105, Cortland, NY 13025, USA; e-mail: alexis.blavos@cortland.edu. 
is defined as "the process of experiencing respiratory impairment from submersion/immersion in liquid" (van Beeck, Branche, Szpilman, Modell, \& Bierens, 2005 , p. 854). From 2005 to 2014 , there were an average of 3,536 deaths annually due to unintentional drowning (nonboating) in the United States (CDC, 2016), and males are at greater risk, accounting for approximately $80 \%$ of all drowning-related deaths (CDC, 2012).

\section{BACKGROUND/LITERATURE REVIEW}

Although drowning rates in the United States have fallen cumulatively in the past 10 years, unintentional drowning continues to rank as one of the leading causes of death among children (CDC, 2012). The danger of drowning is magnified for African American youth, among whom drowning fatalities are 5.5 times higher than among Caucasian children (Gilchrist \& Parker, 2014). Socioeconomic status can serve as a risk or protective factor to children's water safety. For example, children who do not have access to swim lessons, aquatic facilities, and safety products (e.g., life jackets)— not to mention basic knowledge of the danger associated with aquatic activities-are at higher risk of drowning or suffering from a water-related injury (Golob, Giles, \& Rich, 2013). Another issue minorities or persons from lower socioeconomic status may suffer from is inadequate or absent supervision near and in the water (Martin \& Witman, 2010). For children of all races and ethnicities, drowning remains a worldwide problem, with the majority of countries listing it as one of the top three unintentional injury fatalities (Forjuoh, 2013).

Among other prevention strategies, the American Academy of Pediatrics (AAP; 2017) suggests parents enroll their children in formal swim training. Presently, children in the United States lack competence in swimming ability. This deficiency particularly affects African American youth, with $67 \%$ reporting they have poor swimming skills (Irwin, Irwin, Ryan, \& Drayer, 2009). In concordance with the AAP's suggestion, a handful of studies have demonstrated the benefits of enrolling children in formal swim lessons (Irwin et al., 2009; Linnan, Scarr, \& Giersing, 2013). Fortunately, the benefits of water safety education extend to all youth, regardless of race. In one study, a water safety curriculum implemented at a summer camp with $69 \%$ African American children, 28\% Hispanic children, and 3.8\% biracial children-all between prekindergarten to third grade-resulted in increased knowledge regarding water safety among participants of all racial and ethnic groups (Lawson et al., 2012).

Yet it is equally critical to provide water safety education to parents and legal guardians as well. The AAP
(2017) urges parents to keep a watchful eye on their children at all times when in or near the water. Without proper parental supervision, children-particularly toddlers and young children-are at increased risk for drowning, a concern amplified by adults who might underestimate how easily and quickly children can find themselves in harm's way (Brenner et al., 2009). Additionally, after children receive training, parents occasionally have the mistaken belief that their children hold sufficient skills to prevent themselves from drowning, which might not be the case. In one study, parents consistently overestimated their children's level of ability to swim throughout their swim lessons, which may lead to a misjudgment in the amount of supervision their children need (Morrongiello, Sandomierski, Schwebel, \& Hagel, 2013). It is imperative to emphasize the importance of both the child's swimming ability as well as continued parental supervision to reduce youth drowning.

Although parents might not be interested in taking water safety courses for themselves, it is possible they would be amenable to receiving safety information while their children receive instruction. Ideally, parents or legal guardians should receive written materials that reinforce or supplement information learned during swim lessons. These materials would be designed to enhance knowledge, change attitudes, and ultimately change behavior (e.g., increased supervision of their children in and around the water), thereby resulting in increased supervision practices and, in turn, fewer drowning situations (Morrongiello et al., 2013). Yet, in developing an effective intervention, it is fundamental to employ a health behavior theory that has been tested across various behaviors and with diverse populations (Parvanta \& Parvanta, 2011).

The Health Belief Model (HBM) has been one of the most widely used frameworks within health behavior research since the early 1950s. This model was originally developed by the U.S. Public Health Service to increase tuberculosis screenings (Hochbaum, 1958; Rosenstock, 1974). The HBM postulates that certain actions will result in specific outcomes based on the following constructs: perceived susceptibility, perceived severity, self-efficacy, cues to action, perceived barriers, and perceived benefits. Additionally, knowledge is identified as a modifying factor that can influence the aforementioned value expectancies (Champion \& Skinner, 2008). The HBM has been used to address a variety of health behaviors, including smoking, weight loss, contraception, tuberculosis treatment, Internet addiction, HPV vaccination, e-cigarette use, and cancer screening (Abolfotouh et al., 2015; Bayu, Berhe, Mulat, \& Alemu, 2016; Dunn, 2015; Guvenc, Seven, \& Akyuz, 
2016; Tola et al., 2016; Vidourek, King, Rosen, \& Fehr, 2015; Yanhong, Wu, Lau, \& Wang, 2016). Because it was created to explore reasons people were not taking advantage of services that could protect them from disease, the HBM can prove useful in designing and examining effective prevention messages as well (Fishbein \& Cappella, 2006).

The HBM has been used to examine parental perceptions and behaviors regarding injury prevention as well. Specifically, Peterson, Farmer, and Kashani (1990) found that parents' safety behaviors stem from their attitudes and beliefs. In another study, researchers used graphic illustrations to increase perceptions of severity and to increase mothers' knowledge of injury prevention in children under 5 years old (Cheraghi, Poorolajal, Hazavehi, \& Rezapur-Shahkolai, 2014). Chung, Quan, Bennett, Kernic, and Ebel (2014) studied parental roles associated with their children's use of life jackets in open water, but the focus of this study was on modeling behavior of parents and whether they used life jackets themselves. Thus, a dearth of research exists addressing parents' perceptions regarding drowning fatalities in children.

Accordingly, the purpose of this study was to determine if a social marketing campaign guided by the HBM could improve parent's (from the inner city) knowledge and perceptions concerning water safety. A social marketing intervention was selected for this inquiry because, while the focus of this study is to improve parental supervision, it is also critical to teach youth how to swim, as the AAP (2017) strongly recommends that intervention occur at multiple levels. Thus, the $4 P s$ associated with social marketing, Product, Price, Place, and Promotion, were employed to enhance outcomes. More specifically, youth were provided swim lessons with supplemental educational materials targeting their parents (product), at a convenient location (place), for free (price), with prevention messages designed to address perceived threat, benefits, barriers, and self-efficacy in an attempt to favorably influence intentions regarding supervision and other safety practices.

\section{METHOD/STRATEGIES/INTERVENTION APPLICATIONS}

\section{Participants}

Participants for this study were inner-city parents or legal guardians (caregivers) from a large city in the Midwest. A total of 123 caregivers participated in the pretest survey, and 53\% completed the posttest. Thus, 65 matched pairs were included in the current analysis.
The final sample consisted of caregivers of children aged 7 to 16 who were enrolled in a six-session survival swimming course (treatment group; $n=39$ ) or a 3 -week sports camp (no swim lessons or prevention messagescontrol group; $n=26$ ) during the summer. The only demographic difference between the treatment and control groups was the age of the child enrolled in swim lessons $(p<.001)$, a variance not deemed significantly signigicant to the results of this study, given that the primary focus was on parents and legal guardians and not their children.

\section{Design}

Researchers employed a quasi-experimental design with pre- and posttest data to examine the effectiveness of a social marketing campaign designed to increase knowledge, change perceptions, enhance self-efficacy, and create safety-oriented intentions concerning water safety. After receiving institutional review board approval, researchers selected treatment and control groups matched by similar demographics and geographic location (inner city). The treatment group filled out pretest surveys during an orientation program, and the posttest was completed at the final swim lesson. In the control group, participants completed the pretest and posttest on the first and last days of summer camp, respectively. Both treatment and control group participants received $\$ 5$ gift cards to a local restaurant for completing pre- and posttest surveys.

\section{Procedure}

Participants enrolled their children into a six-session, learn-to-swim program and received prevention materials each week the classes were held. On the first day of class, parents and legal guardians obtained a brochure highlighting the dangers associated with aquatic activities. In successive weeks, they were e-mailed a water safety message, were sent a postcard, received a window cling (translucent message hung on a glass or mirror [distributed onsite at the pool]), shown a Facebook message, and finally during the last week of classes, received a text message. Over half the parents reported exposure to the prevention message in each of the channels presented in the campaign, with $100 \%$ stating they received the message in person. The messages were sent out weekly and reinforced with parents during the corresponding swim lesson. Table 1 summarizes the communication channels whereby the six messages were disseminated, along with the corresponding construct from the HBM and the matching exposure rates. 
TABLE 1

Message Distribution

\begin{tabular}{lllr}
\hline Medium & Time & HBM Construct & Received Message \\
\hline Brochure & Week 1 & Perceived Severity & $100 \%$ \\
E-mail message & Week 2 & Perceived Susceptibility & $79.5 \%$ \\
Postcard & Week 3 & Self-Efficacy & $64.1 \%$ \\
Window cling & Week 4 & Cues to Action & $100 \%$ \\
Facebook message & Week 5 & Barriers & $57.9 \%$ \\
Text message & Week 6 & Perceived Benefits & $59 \%$ \\
\hline
\end{tabular}

NOTE: HBM = Health Behavior Model.

\section{Messages}

The prevention messages were created to highlight basic water safety information to parents/legal guardians of inner-city youth. Each of the prevention messages was based off one of the six constructs from the HBM, using social marketing principles. The HBM was selected to underscore the risk of water-based activities (e.g., perceived threat), while attempting to increase self-efficacy (e.g., enhance knowledge) in the event of an emergency.

The first message stated (brochure), "John-Joshua (Josh) Butts tragically died due to a preventable drowning incident. Don't let this happen to your son, daughter, or grandchild" (perceived severity). (Note: as a result of this tragedy, the mother of this child created a non-for-profit water safety organization, which the researchers collaborated with in designing this intervention.) Subsequent messages included, "Drowning is the second leading cause of death for children 14 years old and younger. Be your child's personal Lifeguardwatch over them very closely, when they are near or in the water" (perceived susceptibility; e-mail); "Enroll and reenroll your children in swim lessons, it may save their life" (perceived benefits; text message); "In the event of a water-related emergency, you can save someone's life. Reach, Throw, Don't Go-unless you are rescuing an infant in shallow water, ask someone to call 911, as necessary" (self-efficacy; postcard); "Take your child/children to recreational facilities with a trained lifeguard on duty. Remember a pool tends to be safer than a lake or quarry" (barriers; social media); and "Infants and young children have little to no control over their bodies. You must be within arm's length of them when bathing them or in the water" (cues to action; poster hung in pool area).

Exposure data were collected. The brochure was handed out in person on the first day of swim lessons, with $100 \%$ of parents physically handed the document.
E-mail reader receipts were used with $80 \%$ of participants opening the e-mail. Sixty-four percent of the postcards were delivered to the addressed supplied by parents; undeliverable postcards were returned. Window clings were handed out in person at swim lessons, with $100 \%$ of parents receiving one. The Josh Project has a private social media page, and therefore this message was assessed by social media reports of number of people reached (58\%). Sixty percent of text messages were received via the mobile numbers provided by parents at registration.

\section{Instrument}

The current study used a structural survey instrument to answer the research questions. Development of the questionnaire included a comprehensive literature review of water safety and interventions using the HBM (Becker, 1974, Hochbaum, 1958; Janz \& Becker, 1984, Kirscht, 1974; Rosenstock, 1974). Thirty-five items assessed perceived susceptibility, severity, benefits, barriers, cues to action, and knowledge (five items per construct). The HBM items were measured using 4-point semantic differential or Likert-type scales. Specific item examples from the survey included the following: "How likely is it that the child you care for would drown, if he or she does not learn how to swim?" (perceived susceptibility); "Without my supervision, the child I care for could drown when near or in the water" (perceived severity); "I would feel good about myself if I was able to help someone who was drowning" (perceived benefits); "Not knowing what to do during a water-related emergency could result in a drowning" (perceived barriers); "I am confident that I can adequately watch/supervise the child I care for in and around the pool" (self-efficacy); "I received prevention information in the mail" (cues to action); "I will closely watch the child I care for when near or around the water" (behavioral intention); and "For 
children ages 4 and under, most drowning fatalities occur at or near the home" (response options included true, false, and unsure; knowledge).

Experts in survey design, health behavior theory, and injury prevention research assessed the instrument for face validity. To examine construct validity, a principal component analysis with varimax rotation was conducted on the HBM items. Four components had eigenvalues over Kaiser's criterion of 1 (Larsen \& Warne, 2010), and taken together, these four components-representing perceived threat (i.e., perceived severity and perceived susceptibility combined), perceived benefits, perceived barriers, and self-efficacy-explained $63.32 \%$ of the variance. The other measures were not assessed via principal components analysis either because they were measured on a different scale (cues to action) or because they were not constructs of the HBM (knowledge and behavioral intention). With the exception of behavioral intention (.63), all grouped measures had acceptable to good internal reliability, with Cronbach's alphas ranging from .70 to .83 . Spearman coefficients were calculated to determine temporal stability of the instrument, and all items were found to be statistically significant $(p<.05)$ ranging from .43 to .77 (note: lower values likely due to small sample size).

\section{Data Analysis}

Analyses were performed using IBM SPSS Statistics for Windows, Version 21.0. (IBM Corp, Armonk, NY). Frequencies and percentages were calculated to describe the sociodemographic characteristics of the sample, and $t$ tests were used to assess similarities between the treatment and control groups. An analysis of covariance was used to identify significant differences in posttest scores for each of the constructs in the treatment and control groups, adjusting for pretest scores. Multivariate linear regression was then conducted with pretest scores from both control and intervention groups to determine the HBM constructs' utility in explaining behavioral intentions concerning water safety. Missing data were imputed using series mean.

\section{RESULTS}

\section{Sample Description (Treatment and Control Groups)}

Of the total $(n=65)$ matched pairs, 39 were in the treatment group and 26 in the control group. The majority of caregivers indicated they were the child's parent ( $88.4 \%$ in treatment vs. $100 \%$ in the control), were female $(92 \%$ in both treatment and control), were African American $(78 \%$ in treatment vs. $87 \%$ in control), and had a mean age of 43 years (both groups). Most children were aged 6 to 15 years, with a mean age of 9 years in the treatment group and 11 years in the control group. Participants specified that the child they cared for could swim the following distances: $48 \%$ not at all, $9 \%$ quarter of a pool length, $17 \%$ half pool length, $5 \%$ three quarter of a pool length, and $14 \%$ full pool length or more. All participants indicated they intended to reenroll their child or children into the next set of swim lessons. Table 2 provides a detailed breakdown of the sample in both treatment and control groups.

A chi-square analysis revealed that parent perceptions of their child's swimming ability increased in the treatment group but not the control $\left(\chi^{2}=10.985 ; p=\right.$ .012). Analysis of covariance was then conducted to determine differences between cohorts, adjusting for differences in group pretest scores. Table 3 shows that participants' knowledge and self-efficacy (measured as a summated scale of the responses to these items) in the treatment group changed favorably over the course of the intervention. After controlling for pretest scores, there was a significant difference in treatment and control groups posttest knowledge scores, $F(1,61)=8.15, p$ $=.006, \eta_{p}^{2}=0.1183$. Specifically, the mean values on knowledge from the treatment group increased from $4.46( \pm 1.48)$ on the pretest to $5.69( \pm 0.63)$ on the posttest. There was also a significant difference in treatment and control groups posttest self-efficacy scores, $F(1,61)$ $=4.78, p=.033, \eta_{p}^{2}=0.073$. The mean values of self-efficacy increased from $10.77( \pm 2.95)$ on the pretest to $11.94( \pm 2.55)$ on the posttest.

A multivariate linear regression was then conducted on the pretest surveys of 65 participants in treatment and control groups. Table 4 displays the findings, showing that the HBM constructs (perceived threat, perceived benefits, perceived barriers, and self-efficacy) explained $39.1 \%$ of the variance in behavioral intention, adjusted $R^{2}=0.336, F(1,60)=9.09, p<.01$. Each HBM construct was assessed to see which one best predicted behavioral intention, and perceived threat was found to be the most robust variable $(\beta=$ $.525, p<.01)$.

\section{DISCUSSION}

The ultimate goal of water safety interventions is to reduce the number of unintentional injuries and deaths due to drowning. Of particular concern are African American youth, a demographic group that drowns at disproportionately high rates (CDC, 2012). To address this issue, researchers conducted an exploratory study 
TABLE 2

Demographics

\begin{tabular}{lcc}
\hline Variable & Treatment $(\mathrm{N}=39), \mathrm{n}(\%)$ & Control $(\mathrm{N}=26), n(\%)$ \\
\hline Gender of guardian & $3(7.9)$ & $2(8.0)$ \\
$\quad$ Male & $35(92.1)$ & $23(92.0)$ \\
$\quad$ Female & $5(13.9)$ & $2(8.7)$ \\
Race of guardian & $28(77.8)$ & $20(87.0)$ \\
$\quad$ White & $0(0)$ & $1(4.3)$ \\
African American/Black & $3(8.3)$ & $0(0)$ \\
Asian and Pacific Islander & & $29(85.3)$ \\
Other & $5(14.7)$ & $22(95.7)$ \\
Ethnicity of guardian & $1(4.3)$ & \\
Hispanic & $31(83)$ & $23(92.0)$ \\
Non-Hispanic & $2(5.4)$ & $2(8.0)$ \\
Relationship to child & $3(8.1)$ & $0(0)$ \\
Mother & $1(2.7)$ & $0(0)$ \\
Father & $47.28 \pm 20.74$ & $11.16 \pm 1.66^{*}$ \\
Grandparents & $8.75 \pm 2.35^{*}$ & $43.15 \pm 15.46$ \\
Other & & \\
Age of parent/guardian, $M \pm S D$ (years) & & \\
Age of child, $M \pm S D$ years) & & \\
\hline
\end{tabular}

NOTE: $p$ values were obtained to explore if the groups differ in terms of sociodemographics, percentages may not add up to $100 \%$ due to missing values.

${ }^{*} p<.001$.

TABLE 3

ANCOVA Differences Between Intervention and Control Groups on HBM Measures

\begin{tabular}{ccccccc}
\hline Variable & Group & $\begin{array}{c}\text { Pretest, } \\
\mathrm{M} \pm \mathrm{SD}\end{array}$ & $\begin{array}{c}\text { Posttest } \\
\mathrm{M} \pm \mathrm{SD}\end{array}$ & $\begin{array}{c}\text { Main Effect, } \\
\text { Pretest, } \eta^{2} ; \mathrm{F}\end{array}$ & $\begin{array}{c}\text { Main Effect, } \\
\text { Posttest, } \eta^{2} ; \mathrm{F}\end{array}$ & $\begin{array}{c}\text { Interaction } \\
\text { Effect, } \eta^{2} ; \mathrm{F}\end{array} \quad$ Model $\mathrm{R}^{2}$ \\
\hline Perceived & Treatment & $19.06 \pm 2.98$ & $18.69 \pm 3.76$ & $0.430 ; 41.508^{* *}$ & $0.004 ; 0.202$ & $0.007 ; 0.365$ \\
threat & Control & $15.79 \pm 5.17$ & $15.92 \pm 4.49$ & & & .504 \\
Perceived & Treatment & $19.18 \pm 1.41$ & $19.18 \pm 1.54$ & $0.258 ; 21.202^{* *}$ & $0.001 ; 0.091^{*}$ & $0.001 ; 0.173$ \\
benefits & Control & $19.15 \pm 1.64$ & $18.92 \pm 1.67$ & & & .266 \\
Perceived & Treatment & $18.23 \pm 2.07$ & $18.15 \pm 2.07$ & $0.180 ; 13.210^{* *}$ & $0.000 ; 0.019$ & $0.000 ; 0.012$ \\
barriers & Control & $17.60 \pm 2.22$ & $17.76 \pm 2.35$ & & & .189 \\
Self-efficacy & Treatment & $10.77 \pm 2.95$ & $11.94 \pm 2.55$ & $0.363 ; 30.727^{* *}$ & $0.078 ; 4.543^{*}$ & $0.071 ; 4.133^{*}$ \\
& Control & $11.78 \pm 2.37$ & $12.09 \pm 2.50$ & & & .364 \\
Behavioral & Treatment & $17.39 \pm 1.40$ & $19.94 \pm 11.78$ & $0.017 ; 2.815$ & $0.049 ; 0.964$ & $1.250 ; 0.644$ \\
Intention & Control & $15.48 \pm 2.84$ & $15.60 \pm 1.97$ & & & .100 \\
Knowledge & Treatment & $4.46 \pm 1.48$ & $5.69( \pm 0.63)$ & $0.358 ; 30.145^{* *}$ & $0.272 ; 20.207^{* *}$ & $0.123 ; 7.594^{*}$ \\
& Control & $4.39 \pm 1.73$ & $4.43 \pm 1.44$ & & .561 \\
\hline
\end{tabular}

NOTE: ANCOVA = analysis of covariance; HBM = health behavior model.

${ }^{*} p<.05 .{ }^{* *} p<.001$. 


\begin{tabular}{lcc}
\multicolumn{2}{c}{ TABLE 4} \\
\multicolumn{2}{c}{$\begin{array}{c}\text { Association of the HBM Constructs With Behavioral } \\
\text { Intention }\end{array}$} \\
\hline \multicolumn{2}{c}{$\begin{array}{c}\text { Outcome Variable }= \\
\text { Behavioral Intention }\end{array}$} \\
\cline { 2 - 3 } Predictor Variable & Standardized $\beta$ & $\mathrm{p}$ \\
\hline Threat perception & .525 & .00 \\
Perceived benefits & .217 & .06 \\
Perceived barriers & .095 & .43 \\
Self-efficacy & .072 & .52 \\
\hline
\end{tabular}

NOTE. HBM = health behavior model. Model was constructed using multiple regression using all HBM constructs using the Enter method. Adjusted $R^{2}$ for the model was .336.

to determine if a social marketing campaign targeting parents and guardians of inner-city youth could positively influence knowledge and perceptions concerning water safety. More specifically, this intervention was designed to teach parents and guardians appropriate responses to water-based emergencies, ways to identify safe places to take their child or children they care for swimming, and the importance of close supervision near water.

Using social marketing principles, swim lessons were provided to youth with supplemental educational materials targeting their parents (product), at a convenient location (place), for free (price), with prevention messages (promotion). The research team worked in conjunction with the university's marketing department to create six separate water safety messages. The theoretical underpinnings for the messages were based from the HBM (Becker, 1974; Hochbaum, 1958; Kirscht, 1974; Rosenstock, 1974). Each message (brochure, postcard, text message, e-mail, Facebook message, and a window cling) targeted one construct from the HBM: perceived threat, perceived benefits, perceived barriers, self-efficacy, behavioral intention, and knowledge.

Consistent with the extant literature, the HBM was effective in mitigating parents' perceptions of injury prevention with their children (Cheraghi et al., 2014; Chung et al., 2014; Morrongiello \& Kiriakou, 2004; Peterson et al., 1990). The most important finding from this study is that participants who received the intervention had significant gains in knowledge and self-efficacy. The change in knowledge from pretest to posttest indicated an increase in general knowledge of water safety, including correctly identifying the risk factors associated with drowning among youth. Additionally, participants indicated they felt more confident supervising their children while near or in the water, as well as responding to an emergency.

While perceived threat, benefits, barriers, and behavioral intentions did not vary from treatment to control group, these constructs merit additional research due to the limitations associated with this research. Indeed, low participation numbers may have resulted in Type II error (failing to detect an effect that was present). For example, although the mean average value for behavioral intention increased in the treatment group, it was not statistically significant, perhaps due to lack of power. Another issue potentially skewing the behavioral intention variable was social desirability. Not many parents/legal guardians would likely admit to anything less than steadfast intentions (i.e., strongly agreeing) to supervise their child/children closely when near or in the water, yet statistics continue to prove this monitoring does not happen on a consistent basis. Finally, because a quasi-experimental study design was used for this study, the results from may be due to the characteristics of the cohort rather than the intervention. However, the pre-post assessment design minimizes internal threats to validity.

The demographic distribution of the sample for this study merits discussion as well. The sample was obtained from parents from the inner city, and the majority of participants were female (92\%). Clearly, there is an opportunity to involve fathers, extended family members, and friends in water safety/prevention and future research as any bystander may encounter an emergency. From a prevention perspective, the more adults supervising their children in and near the water the better. Equally important, people typically do not learn how to swim with only one set of lessons, so water safety instructors should encourage their students to take subsequent swim lessons. The results from the current study indicated all (100\%) of the parents/guardians planned to reenroll their child/children for another set of swim lessons. Thus, from a long-term perspective, turning students and their parents/legal guardians on to swimming may be just as important as the skills they develop; customer satisfaction is a major consideration in advancing prevention efforts.

\section{CONCLUSIONS}

The findings from this study showed an increase in parents or legal guardians' knowledge and self-efficacy concerning water safety, and the HBM constructs predicted nearly $40 \%$ of the variance in participants' behavioral intention to closely supervise their children in or near the water. Since perceived threat was the strongest predictor of behavioral intention, researchers 
and practitioners may want to increase parents' perceptions of severity and their child's susceptibility to drowning when designing water safety interventions. That recommendation notwithstanding, it is irresponsible to use a "fear appeal" to motivate behavior change without providing information on how to address the behavior of interest.

Although providing swim lessons is crucial to children's well-being in that the lessons equip them with essential water safety skills, swim lessons nonetheless only intervene on one socioecological level of influence: the children themselves. Accordingly, the present study featured a social marketing campaign that addressed additional socioecological levels focusing on the "product." The product within social marketing is divided into three levels: the core product (e.g., preventing drowning), the actual product (e.g., swim lessons), and the augmented product (e.g., brochure, window cling, etc.; Lee \& Kotler, 2016). Indeed, practitioners can use the results from this study to augment traditional approaches by educating parents about water safety, thus providing added reinforcement of the critical skills gained from swim lessons. Data on exposure may also be useful as health educators seek less expensive ways for health communication. To that end, our approach addressed the public health issue of drowning in a pragmatic way at both the individual level (swim lessons for children), as well as the interpersonal level (parental supervision).

\section{REFERENCES}

Abolfotouh, M. A., BaniMustafa, A. A., Mahfouz, A. A., Al-Assiri, M. H., Al-Juhani, A. F., \& Alaskar, A. S. (2015). Using the health belief model to predict breast self-examination among Saudi women. BMC Public Health, 15, 1163. doi:10.1186/s12889-015-2510-y

American Academy of Pediatrics. (2017). AAP gives updated advice on drowning prevention. Retrieved from https://www.aap. org/en-us/about-the-aap/aap-press-room/pages/AAP-GivesUpdated-Advice-on-Drowning-Prevention.aspx

Bayu, H., Berhe, Y., Mulat, A., \& Alemu, A. (2016). Cervical cancer screening service uptake and associated factors among age eligible women in Mekelle zone, northern Ethiopia, 2015: A community based study using health belief model. PLoS One, 11(3), e0149908. doi:10.1371/journal.pone.0149908

Becker, M. H. (1974). The health belief model and personal health behavior. Health Education Monographs, 2, 324-473.

Brenner, R. A., Taneja, G., Haynie, D. L., Trumble, A. C., Qian, C., Klinger, R. M., \& Klebanoff, M. A. (2009). Association between swimming lessons and drowning in childhood: A case-control study. Archives of Pediatrics \& Adolescent Medicine, 163, 203210. doi:10.1001/archpediatrics.2008.563

Centers for Disease Control and Prevention. (2012). DrowningUnited States, 2005-2009. Morbidity and Mortality Weekly Report, $61,344-347$
Centers for Disease Control and Prevention. (2016). Unintentional drowning: Get the facts. Retrieved from http://www.cdc.gov/ HomeandRecreationalSafety/Water-Safety/waterinjuries-fact sheet.html

Champion, V. L., \& Skinner, C. S. (2008). The Health Belief Model. In K. Glanz, B. K. Rimer, \& K. Viswanath (Eds.), Health behavior and health education: Theory, research, and practice (4th ed., pp. 41-66). San Francisco, CA: Jossey-Bass.

Cheraghi, P., Poorolajal, J., Hazavehi, S. M. M., \& RezapurShahkolai, F. (2014). Effect of educating mothers on injury prevention among children aged $<5$ years using the health belief model: A randomized trial. Public Health, 128, 825-830.

Chung, C., Quan, L., Bennett, E., Kernic, M. A., \& Ebel, B. E. (2014). Informing policy on open water drowning prevention: An observational survey of life jacket use in Washington state. Injury Prevention, 20, 238-243. doi:10.1136/injuryprev-2013-041005

Dunn, M. S. (2015). College student's behavior, health beliefs, norms, and intentions to use e-cigarettes. American Journal of Health Studies, 30, 105-109.

Fishbein, M., \& Cappella, J. N. (2006). The role of theory in developing effective health communications. Journal of Communication, 56, S1-S17.

Forjuoh, S. N. (2013). Water safety and drowning prevention. International Journal of Injury Control and Safety Promotion, 20, 207-208. doi:10.1080/17457300.2013.822634

Gilchrist, J., \& Parker, E. M. (2014). Racial and ethnic disparities in fatal unintentional drowning among persons less than 30 years of age-United States, 1999-2010. Journal of Safety Research, 50, 139-142. doi:10.1016/j.jsr.2014.06.001

Golob, M. I., Giles, A. R., \& Rich, K. M. (2013). Enhancing the relevance and effectiveness of water safety education for ethnic and racial minorities. International Journal of Aquatic Research and Education, 7(1), 39-55.

Guvenc, G., Seven, M., \& Akyuz, A. (2016). Health belief model scale for human papilloma virus and its vaccination: Adaptation and psychometric testing. Journal of Pediatric \& Adolescent Gynecology, 29, 252-258. doi:10.1016/j.jpag.2015.09.007

Hochbaum, G. M. (1958). Public participation in medical screening programs: A socio-psychological study. Washington, DC: U.S. Department of Health, Education, and Welfare, Public Health Service, Bureau of State Services, Division of Special Health Services, Tuberculosis Program.

Irwin, C. C., Irwin, R. L., Ryan, T. D., \& Drayer, J. (2009). Urban minority youth swimming (in)ability in the United States and associated demographic characteristics: Toward a drowning prevention plan. Injury Prevention, 15, 234-239.

Janz, N. K., \& Becker, M. H. (1984). The health belief model: A decade later. Health Education Quarterly, 11, 1-47. doi:10.1177/ 109019818401100101

Kirscht, J. P. (1974). The health belief model and illness behavior. Health Education Monographs, 2, 2387-2408.

Larsen, R., \& Warne, R. T. (2010). Estimating confidence intervals for eigenvalues in exploratory factor analysis. Behavior Research Methods, 42, 871-876. doi:10.3758/BRM.42.3.871

Lawson, K. A., Duzinski, S. V., Wheeler, T., Yuma-Guerrero, P. J., Johnson, K. M., Maxson, R. T., \& Schlechter, R. (2012). Teaching safety at a summer camp: Evaluation of a water safety curriculum 
in an urban community setting. Health Promotion Practice, 13, 835-841.

Lee, R. L., \& Kotler, P. (2016). Social marketing: Changing behaviors for good (5th ed.). Thousand Oaks, CA: Sage.

Linnan, M., Scarr, J., \& Giersing, M. (2013). Toward a world where children do not drown. JAMA Pediatrics, 167, 110-111. doi:10.1001/jamapediatrics.2013.948

Martin, N. T., \& Witman, D. (2010). Factors affecting minority downing. International Journal of Aquatic Research and Education, 4, 9-18.

Morrongiello, B. A., \& Kiriakou, S. (2004). Mothers' home-safety practices for preventing six types of childhood injuries: What do they do, and why? Journal of Pediatric Psychology, 29, 285-297.

Morrongiello, B. A., Sandomierski, M., Schwebel, D. C., \& Hagel, B. (2013). Are parents just treading water? The impact of participation in swim lessons on parents' judgments of children's drowning risk, swimming ability, and supervision needs. Accident Analysis \& Prevention, 50, 1169-1175. doi:10.1016/j.aap.2012.09.008

Parvanta, C., \& Parvanta, S. (2011). Persuasive health communications: The role of theory. In C. F. Parvanta, S. Parvanta, D. E. Nelson, \& R. N. Harner (Eds.), Essentials of public health communication (pp. 147-158). Sudbury, MA: Jones \& Bartlett Learning. Peterson, L., Farmer, J., \& Kashani, J. H. (1990). Parental injury prevention endeavors: A function of health beliefs? Health Psychology, 9, 177-191.

Rosenstock, I. (1974). Historical origins of the health belief model. Health Education \& Behavior, 2, 328-335. doi:10.1177/109019817 400200403

Tola, H. H., Shojaeizadeh, D., Tol, A., Garmaroudi, G., Yekaninejad, M. S., Kebede, A., . . . Klinkenberg, E. (2016). Psychological and educational intervention to improve tuberculosis treatment adherence in Ethiopia based on health belief model: A cluster randomized control trial. PLoS One, 11, e0155147. doi:10.1371/ journal.pone.0155147

van Beeck, E. F., Branche, C. M., Szpilman, D., Modell, J. H., \& Bierens, J. J. L. M. (2005). A new definition of drowning: Towards documentation and prevention of a global public health problem. Bulletin of the World Health Organization, 83, 853-856.

Vidourek, R. A., King, K. A., Rosen, B. L., \& Fehr, S. K. (2015). Using the health belief model to explore female's perceptions of male HPV vaccination. American Journal of Health Studies, 30, 187-195.

Yanhong, W., Wu, A. M. S., Lau, J. T. F., \& Wang, Y. (2016). The health belief model and number of peers with internet addiction as inter-related factors of Internet addiction among secondary school students in Hong Kong. BioMed Central Public Health, 16, 272. doi:10.1186/s12889-016-2947-7 